\title{
MODO E GRADAÇÃO: UMA ANÁLISE DA INVESTIGAÇÃO SOBRE O CONJUNTIVO DE VILLALTA
}

\author{
Ana Bárbara Pedrosa ${ }^{1}$
}

\begin{abstract}
Resumo
Aqui verificaremos se a tese de Villalta (2009), segundo a qual os predicados que seleccionam o modo conjuntivo são analisados como predicados graduáveis, se verifica, e ainda se se aplica à língua portuguesa. Testaremos ainda as hipóteses de Hooper (1975) e Palmer (1986) sobre a seleção do indicativo pelos predicados assertivos e do conjuntivo pelos não-assertivos. Analisaremos ainda a proposta de Marques (2010), que diz que a seleção entre os modos deve ser condicionada pela verificidade e pela atitude expressa pela proposição e pelo efeito que esta tem no context set. Referindo-nos ao que Villalta não referiu, analisaremos ainda os predicados declarativos negativos, directos, de medo e causativos, assim como as frases iniciadas por talvez.
\end{abstract}

Palavras-chave: Conjuntivo. Predicados. Graduáveis. Seleção. Assertivos.

\section{MOOD AND GRADABILITY: AN ANALYSIS OF VILLALTA'S RESEARCH ON THE SUBJUNTIVE}

\begin{abstract}
Here we verify Villalta's thesis on Spanish (2009), according to which all the predicates that select the subjunctive mode are analysed as gradual predicates, and also if it is applied to Portuguese. We also test the hypothesis brought by Hooper (1975) and Palmer (1986) about the selection of the indicative by the assertive predicates and the selection of the subjunctive by the non-assertive predicates. We analyse Marques's proposal (2010), that says that the selection among the modes should be conditioned by the verity and the attitude expressed by the preposition and the effect that it has on the context sex. We also verify how the negative declarative predicates, the direct predicates, the predicates of fear and the causative predicates select the mode, as well as the phrases initiated by talvez ("maybe)".
\end{abstract}

Keywords: Subjunctive. Predicates. Gradual. Selection. Assertive.

\section{INTRODUÇÃO}

No artigo "Mood and gradibility: an investigation of the subjunctive mood in Spanish", publicado em 2009, Elisabeth Villalta faz uma análise dos predicados que selecionam o modo subjuntivo em espanhol, baseando-se numa semântica de comparação. A generalização principal que propõe é a seguinte: em espanhol, um predicado seleciona o modo subjuntivo na sua proposição subordinada se a proposição for comparada às suas alternativas contextuais numa escala introduzida pelo predicado. Nesta proposta, os predicados que

\footnotetext{
${ }^{1}$ Linguista na Google. Doutora em Ciências Humanas pela Universidade Federal de Santa Catarina (UFSC), Florianópolis - Santa Catarina - Brasil. E-mail: anabarbarapedrosa@gmail.com
} 
selecionam o modo subjuntivo são analisados como predicados graduáveis. Villalta (2009) irá ainda explicar o papel que o modo subjuntivo desempenha na composição semântica da frase. Verificaremos aqui se a tese apresentada pela autora pode ou não ser aplicada à língua portuguesa, ou seja, se as regras que levam à selecção do modo em subjuntivo em espanhol podem ser aplicadas ao caso português.

A discussão que aqui apresentamos irá limitar-se, como se limitou o artigo de Villalta (2009), à discussão das características dos predicados que seleccionam o modo subjuntivo. Pretende-se, com este estudo, chegar a uma melhor compreensão das razões pelas quais as formas dos verbos no subjuntivo requerem condições semânticas especiais e por que razão não são obrigatórias em alguns contextos.

\section{A DISTRIBUIÇÃO DO MODO CONJUNTIVO NAS FRASES COMPLETIVAS EM ESPANHOL E EM PORTUGUÊS}

Villalta (2009) começa por dizer que, em espanhol, um dos factores que determinam se o verbo de uma frase subordinada deve estar no indicativo ou no subjuntivo é a oração subordinante. Assim, o modo indicativo será seleccionado por verbos epistémicos, predicados de comunicação, de certeza, promissivos, verbos de ficção, predicados de julgamento mental e predicados de percepção (VILLALTA, 2009, p. 469). Verificamos pelos seguintes exemplos que a tese apresentada pela autora concernente à língua espanhola é também aplicável à portuguesa:

(1) O Manuel acha que vai chover.

(2) O Manuel sabe que choveu.

(3) O Manuel disse que queria ver.

(4) O Manuel prometeu que vai trazer o livro.

Por sua vez, o modo subjuntivo será seleccionado em espanhol por predicados desiderativos, emotivos-factivos, modais, predicados epistémicos negativos, deônticos e causativos (VILLALTA, 2009, p. 470). Verificamos que, em português, os mesmo tipos de predicados também selecionam o subjuntivo .

(5) O Manuel quer que venhas.

(6) O Manuel lamenta que estejas aí. 


\section{Linguagens - Revista de Letras, Artes e Comunicação - ISSN 1981- 9943 \\ Blumenau, v. 12, n. 3, p. 368-378, set./dez. 2018 \\ DOI: http://dx.doi.org/10.7867/1981-9943.2018v12n3p368-378}

(7) É possível que venha.

(8) Duvidamos que esteja em Paris.

(9) Ordeno-te que saias.

(10) Fiz com que fosse rápido.

A autora, contudo, não faz referência a outros predicados que seleccionam o conjuntivo, como os seguintes: declarativos negativos ("Nego que tenha ido"), directivos ("Sugiro-te que leias"), predicados de medo ("Temo que também venha") e predicados causativos ("Implicou que perdesse o emprego"). Será também de notar que, em ambas as línguas, todas as frases iniciadas por talvez pedem o subjuntivo, facto a que Villalta (2009) não faz referência.

A autora nota ainda que, em ambas as categorias, encontramos tanto predicados factivos como predicados não-factivos e argumenta que as frases que contêm predicados factivos pressupõem que a proposição expressa pela frase subordinada é verdadeira, acontecendo o inverso nas frases com predicados não-factivos (VILLATA, 2009, p. 470). De facto, o indicativo tem sido visto como o modo da verdade, seleccionado sempre que se pressupõe a verdade da oração subordinada, sendo o conjuntivo a marca do hipotético, como se houvesse uma regra absoluta que relacionasse a selecção do conjuntivo com a inverdade da proposição. Contudo, verbos factivos como lamentar vêm mostrar que esta não é uma teoria adequada. Rui Marques, que propõe uma nova análise das condições que levam à selecção dos modos, vem considerar que esta dificuldade será "inultrapassável por qualquer teoria que assuma uma relação entre modo e verdade da frase, já que no conjunto de verbos que seleccionam conjuntivo há um grupo que não permite inferir que a sua proposição complemento é verdadeira" (MARQUES, 1998, p. 194). Por este motivo, julga que "será erróneo tentar estabelecer uma correspondência entre a selecção do indicativo ou do conjuntivo e o valor de verdade da proposição em causa" (MARQUES, 1998, p. 194). Fica, portanto, patente que não é possível assumir que a selecção dos modos se baseia apenas na crença na verdade, ou não, da proposição.

Hooper (1975) diz que, na maioria das línguas românticas, os predicados assertivos seleccionam o indicativo e os não-assertivos seleccionam o conjuntivo. Esta assunção virá a encontrar contradição em Palmer (1986), que repara que esta generalização falha no que concerne aos casos em que o modo indicativo é seleccionado em frases interrogativas, num contexto claramente não-assertivo. A tese de Hooper não será, por isso, suficiente ou adequada à explicitação das razões que levam à selecção de um ou de outro modo. 


\section{Linguagens - Revista de Letras, Artes e Comunicação - ISSN 1981- 9943 \\ Blumenau, v. 12, n. 3, p. 368-378, set./dez. 2018 \\ DOI: http://dx.doi.org/10.7867/1981-9943.2018v12n3p368-378}

Num artigo sobre a seleção de modo no português europeu, Rui Marques (2010) propõe que a seleção entre os modos seja condicionada não só pela veridicidade, mas também pela atitude expressa pela proposição e pelo efeito que a asserção da proposição tem no context set (MARQUES, 2010, p. 135). Já anteriormente o autor havia defendido uma hipótese alternativa: o modo seria uma "expressão da modalidade, estando a selecção de modo em orações completivas relacionada com o tipo de atitude a que está associado o verbo matriz" (MARQUES, 1998, p. 195). O autor irá considerar que "todos os verbos que selecionam o indicativo expressam uma atitude de conhecimento ou crença, ou seja, uma atitude de natureza epistémica ou doxástica" (MARQUES, 2010, p. 143). Existe ainda um conjunto de verbos epistémicos que podem seleccionar o modo conjuntivo, como supor ou acreditar. O modo que seleccionam irá depender do grau de crença que a proposição expressa. De acordo com o modo seleccionado, observa-se também uma alteração do significado. Atentemos nos seguintes exemplos:

(11) Ela procura uma secretária que fala espanhol.

(12) Ela procura uma secretária que fale espanhol.

A frase (11), que selecciona o modo indicativo, permite inferir que, de facto, existe uma secretária que fala espanhol; a frase (12), contudo, ao seleccionar o conjuntivo, deixa a hipótese de que essa secretária não exista. Há, assim, uma relação direta entre a seleção de modo e a interpretação das frases.

Como Marques acaba por concluir, a seleção de modo está relacionada com o tipo de atitude expressa na proposição (MARQUES, 2004, p. 96), ou seja, “o modo é a expressão da realidade" (MARQUES, 1998, p. 97). O autor nota ainda que, nos verbos não-factivos que regem o conjuntivo, "não existe um traço comum a todos eles, no que diz respeito a uma possível tipologia de atitude" (MARQUES, 1998, p. 196). Nos não-factivos que regem o indicativo, contudo, há um traço comum: "todos os verbos (não-factivos) regentes de indicativo estão associados à expressão de uma atitude de crença, permitindo inferir que a sua proposição complemento é tida como verdadeira pelo sujeito da frase matriz" (MARQUES, 1998, p.196). Os verbos declarativos, ao descreverem uma acção cujo agente é o sujeito da frase matriz, "permitem inferir que tal entidade se compromete com a verdade da sua proposição complemento", exprimindo também uma atitude de crença (MARQUES, 1998, p. 197). 


\section{Linguagens - Revista de Letras, Artes e Comunicação - ISSN 1981- 9943 \\ Blumenau, v. 12, n. 3, p. 368-378, set./dez. 2018 \\ DOI: http://dx.doi.org/10.7867/1981-9943.2018v12n3p368-378}

Marques verifica ainda que a selecção do indicativo em frases negativas parece deverse ao facto de ser expressa numa atitude epistémica, enquanto o conjuntivo é seleccionado nos casos em que existe outra atitude modal (MARQUES, 1998, p. 200). Conclui, assim, que "o modo indicativo é seleccionado para um contexto modal particular, nomeadamente um contexto modal epistémico, enquanto o subjuntivo é selecionado para os outros contextos modais" (MARQUES, 2004, p. 98). Ou seja, infere-se daqui que o subjuntivo será um modo por defeito, sendo seleccionado nos contextos em que o modo indicativo não o é.

No artigo de Villalta (2009), é dada uma atenção particular aos predicados sentir e dizer, que, em espanhol, podem seleccionar tanto o conjuntivo como o indicativo. Essa regra, ainda que, em português, funcione para o predicado dizer, não funcionará para o sentir. A autora afirma que o predicado sentir pode ser interpretado como um predicado emotivo factivo, seleccionando o modo subjuntivo, ou como um predicado de percepção, seleccionando o modo indicativo. Já Klein-Andreu (1990) havia notado que, em espanhol, o verbo sentir, quando a frase subordinada está no indicativo, é equivalente a notar, sendo equivalente a lamentar quando está no subjuntivo. Ou seja, a interpretação dos verbos difere consoante o modo que seleccionem. Em português, contudo, sentir não é um predicado emotivo factivo, sendo sempre de percepção, a não ser quando precede o quantificar muito ("Sinto muito que o teu pai tenha morrido"). Por outro lado, o que a autora diz sobre o predicado dizer pode ser aplicado à língua portuguesa: o predicado pode ser interpretado como um predicado de comunicação, seleccionando o modo indicativo (13), ou como um predicado directivo, seleccionando o subjuntivo (14). Verificamos que o mesmo acontece em português:

(13) Digo-te que acabo a tempo.

(14) Disse-te que acabasses a tempo.

\section{UMA SEMÂNTICA CONDICIONAL PARA PREDICADOS QUE SELECCIONAM O MODO SUBJUNTIVO}

Villalta defende que os predicados que seleccionam o modo subjuntivo em espanhol introduzem uma relação de ordem. A relação de ordem permite descrever diferentes graus de aproximação ao ideal, o que dá conta da gradação da modalidade. Segundo a autora, essa relação pode ser de desejabilidade ou de probabilidade, como acontece com predicados como surpreender-se ou duvidar (VILLALTA, 2009, p. 475). 


\section{Linguagens - Revista de Letras, Artes e Comunicação - ISSN 1981- 9943 \\ Blumenau, v. 12, n. 3, p. 368-378, set./dez. 2018 \\ DOI: http://dx.doi.org/10.7867/1981-9943.2018v12n3p368-378}

A análise de predicados desiderativos de Heim (1992) mostra que cada predicado desiderativo contém uma condicional escondida: "A little more explicity, the leading intuition is that John wants you to leave means that John thinks that if you leave he will be in a more desirable world than if you don't" (HEIM, 1992, p. 193). Villalta (2009) adopta a semântica de Heim (1992) para caracterizar os predicados que seleccionam o subjuntivo em espanhol. Para isso, irá focar-se em dois assuntos: a comparação de alternativas contextuais e as alternativas doxásticas.

\subsection{A COMPARAÇÃO DAS ALTERNATIVAS CONTEXTUAIS}

Villalta (2009) defende que a semântica dos predicados que seleccionam o subjuntivo em espanhol envolve a comparação da proposição subordinada $\mathrm{p}$ com alternativas contextualmente disponíveis e que, nas condições de verdade, as referências às crenças do sujeito podem ser substituídas pelo conjunto de alternativas contextualmente disponíveis (VILLALTA, 2009, p. 476).

\subsubsection{Quando mais do que duas alternativas contextuais estão disponíveis}

A semântica adoptada até agora é baseada num caso especial em que o contexto só providencia as alternativas $\mathrm{p} e \neg$. Contudo, há contextos que providenciam mais do que duas alternativas. Villalta (2009, p. 477) deixa o seguinte exemplo:

\footnotetext{
Sofia prometeu trazer uma sobremesa para o piquenique. Vitória acredita que há três possibilidades. Ela pode fazer um bolo de chocolate, ainda que Vitória ache que é altamente improvável, devido ao trabalho que dá. Pode trazer uma tarte de maçã, o que Vitória considera muito provável, já que ela pode comprar uma na pastelaria. Ou pode trazer um gelado, o que lhe parece ainda mais provável, já que ela costuma ter algum no congelador. Vitória prefere o bolo de chocolate à tarte da maçã e a tarte de maçã ao gelado.
}

Neste contexto, há duas escalas envolvidas: uma diz respeito à desejabilidade e outra à probabilidade. Villalta (2009) conclui que a semântica dos predicados sob discussão envolve a comparação de p com o conjunto das suas alternativas contextuais em vez de apenas $\neg$ p.

\subsubsection{As alternativas doxásticas}




\section{Linguagens - Revista de Letras, Artes e Comunicação - ISSN 1981- 9943 \\ Blumenau, v. 12, n. 3, p. 368-378, set./dez. 2018 \\ DOI: http://dx.doi.org/10.7867/1981-9943.2018v12n3p368-378}

Villalta (2009) argumenta ainda que, na semântica de Heim para os predicados de desejo (1992), os desejos do sujeito estão demasiado ligados às suas crenças, dizendo que a semântica de Heim prevê que, para frases que contenham predicados de desejo, certas inferências sejam possíveis, ao contrário das nossas intuições. Dá o exemplo de uma situação em que as escolhas de alguém para o horário de trabalho do semestre seguinte dependam da quantidade de trabalho que conseguir levar a cabo no semestre actual. Assim, no seguinte exemplo, a conclusão (c) nunca pode ser inferida:

a) Quero ensinar às terças e quintas no próximo semestre.

b) Acho que vou ensinar às terças e quintas no próximo semestre se e só se trabalhar muito agora.

c) Quero trabalhar muito agora.

A semântica condicional para o verbo querer, contudo, prevê que esta inferência deva ser válida (VILLATA, 2009, p. 478). A inferência inválida mostra que alguém pode acreditar que as proposições p e q são verdadeiras no mesmo conjunto de mundos e, ao mesmo tempo, querer $\mathrm{p}$ sem querer q. A semântica de Heim não pode capturar este facto. Como consequência, Villalta propõe eliminar a referência às alternativas doxásticas e simplesmente substitui-las pelo grupo de alternativas contextualmente relevantes (VILLALTA, 2009, p. 479).

\subsubsection{Nova hipótese para o modo conjuntivo em espanhol}

Villalta (2009) propõe que a semântica baseada na comparação de alternativas contextuais possa ser estendida a todos os predicados que seleccionam o modo subjuntivo em espanhol: "uma proposição p que é o complemento do predicado matriz pede o modo subjuntivo se o predicado da matriz introduzir uma relação de ordem entre as proposições e comparar $p$ às suas alternativas contextualmente disponíveis" (VILLALTA, 2009, p. 481). A proposta que faz envolve a comparação de alternativas contextuais às proposições expressadas pela frase subordinada.

\subsection{VILLALTA: AS CLASSES DE PREDICADOS QUE SELECCIONAM O SUBJUNTIVO EM ESPANHOL}




\section{Linguagens - Revista de Letras, Artes e Comunicação - ISSN 1981- 9943 \\ Blumenau, v. 12, n. 3, p. 368-378, set./dez. 2018 \\ DOI: http://dx.doi.org/10.7867/1981-9943.2018v12n3p368-378}

Nos predicados desiderativos e emotivos factivos, o primeiro factor de variação será a dimensão da escala, que pode variar de predicado para predicado: predicados desiderativos contribuem para uma relação de ordem de desejabilidade; predicados emotivos factivos podem contribuem para uma relação de desejabilidade ou para uma relação inversa de desejabilidade. Villalta (2009) defende, assim, que os predicados graduáveis contribuem directamente para a dimensão da escala envolvida (VILLALTA, 2009, p. 482). O segundo factor de variação será a classificação de $\mathrm{p}$ entre as alternativas. A proposta desenvolvida deixa espaço para expressar que p pode ser o melhor, o pior ou apenas uma boa alternativa.

A autora refere ainda os verbos modais, dizendo-os associados à escala de probabilidade. De fato, os verbos modais são os verbos que expressam vários tipos de modalidade de maneira mais clara e directa. A modalidade é sempre relativa, razão pela qual estes verbos são contextualmente dependentes e não ambíguos. As frases que incluem este tipo de verbos são interpretadas relativamente à sua base modal e à relação de ordem que é definida no conjunto de mundos possíveis.

Nos predicados diretivos, a relação de ordem para a qual o predicado contribuiu pode variar. Em Portner (2007), a ordem pode variar de acordo com o que o imperativo expressa.

Nos casos de causativos como fazer ou alcançar, Villalta (2009) propõe que a relação de comparação relevante seja uma de similaridade comparativa. As causativas são geralmente analisadas com a semântica das condicionais.

Villalta sugere que predicados como fazer e alcançar contenham a causa predicado como parte do seu significado. Assim, como nos predicados directivos, a comparação relevante estará subordinada mais profundamente no significado do predicado. Os causativos partilham com as outras classes de predicados o facto de contribuírem para a relação de ordem e comparam $p$ às suas alternativas contextuais.

\section{INFERÊNCIAS PRÁTICAS}

Uma semântica de necessidade ou possibilidade modal não pode capturar uma propriedade importante dos predicados que seleccionam o modo conjuntivo (VILLALTA, 2009, p. 489).

A autora apresenta um exemplo que mostra que, na conclusão de certas inferências práticas, não podemos substituir o verbo modal (que expressa necessidade) pelo predicado querer. Sob a assumpção de que ambos os predicados são analisados com a semântica de 


\section{Linguagens - Revista de Letras, Artes e Comunicação - ISSN 1981- 9943 \\ Blumenau, v. 12, n. 3, p. 368-378, set./dez. 2018 \\ DOI: http://dx.doi.org/10.7867/1981-9943.2018v12n3p368-378}

necessidade modal, esperamos que isto seja possível. Com as premissas a e b podemos inferir c, mas não d.

(a) Marcela quer ir ao piquenique.

(b) Marcela acredita que só pode ir ao piquenique se trabalhar horas extra.

(c) Marcela devia trabalhar horas extra.

(d) Marcela quer trabalhar horas extra.

Sob a assumpção de que querer recebe uma semântica de necessidade modal, a autora prevê que d deva ser uma inferência válida, como c (VILLALTA, 2009, p. 489). As inferências práticas providenciam, assim, um argumento contra uma semântica de necessidade modal. Pelo contrário, uma semântica baseada na comparação de alternativas contextuais captura o fenómeno de maneira directa: na proposta de Villalta, não há expectativa de que a inferência também inclua o predicado querer.

\subsection{PREDICADOS GRADUÁVEIS}

Predicados de gradação como alto expressam propriedades que induzem uma relação de ordem: podemos comparar indivíduos de acordo com a propriedade de serem mais ou menos altos. A diferença crucial entre predicados graduáveis e não graduáveis é que os domínios de predicados graduáveis podem ser parcialmente ordenados de acordo com alguma propriedade de gradação, enquanto os domínios de propriedades não graduáveis não podem (VILLALTA, 2009, p. 508)

Para os adjectivos, modificadores como muito indicam a natureza graduável/não graduável. A frase a) expressa que a vítima é alta até um certo nível, mas a b) não pode expressar que a vítima está morta até um certo nível:

(a) A vítima é muito alta.

(b) A vítima está muito morta. (VILLALTA, 2009, p. 508)

Muitos predicados que seleccionam o modo subjuntivo em espanhol permitem modificadores como enormemente. $\mathrm{O}$ mesmo se verifica em português:

(a) Marcela deseja enormemente que o Rafael venha. 


\section{Linguagens - Revista de Letras, Artes e Comunicação - ISSN 1981- 9943 \\ Blumenau, v. 12, n. 3, p. 368-378, set./dez. 2018 \\ DOI: http://dx.doi.org/10.7867/1981-9943.2018v12n3p368-378}

(b) Sofía alegra-se enormemente por virem visitá-la.

Nenhuma das classes de predicados que seleccionam o modo indicativo permite a modificação com advérbios como enormemente. A incompatibilidade com estes verbos é ilustrada com o predicado epistémico saber e o de comunicação dizer.

(a) Sofia sabia enormemente que não podia vir.

(b) Alberto disse enormemente que tinha fome.

Todos os predicados que seleccionam o subjuntivo permitem modificação com muitos modificadores, como muito, bastante, tanto e demasiado. Pelo contrário, com predicados que seleccionam o indicativo, estes modificadores são inaceitáveis ("Rafael sabe muito que não tem razão", "Rafael promete muito que poderá vir"). Assim, para os predicados que seleccionam ambos, a modificação de nível só é possível quando o subjuntivo é seleccionado.

Entre os predicados que seleccionam o modo indicativo, uma excepção é feita para a classe dos predicados de certeza como estar seguro: "Victoria está segura de que Sofia trará um bolo de chocolate" (VILLALTA, 2009, p. 512). Mais uma vez, a tese de Villalta pode ser aplicada à língua portuguesa.

\section{CONCLUSÕES}

A autora não faz referências a todos os tipos de predicados que seleccionam o conjuntivo, não mencionando os declarativos negativos, os directivos, os predicados de medo e os causativos. Também não se refere ao facto de que todas as frases iniciadas por talvez pedem o conjuntivo. Estas regras, contudo, aplicam-se à língua espanhola e à portuguesa. Os predicados que seleccionam o modo subjuntivo introduzem uma relação de ordem, permitindo descrever diferentes graus de aproximação ao ideal. A proposta da autora, de que a semântica baseada na comparação de alternativas contextuais possa ser estendida a todos os predicados que seleccionam o modo subjuntivo em espanhol, também se aplica ao português.

Os verbos modais, expressando de maneira clara e directa vários tipos de modalidades, estão associados à escala de probabilidade. As frases que incluem este tipo de verbos são interpretadas relativamente à sua base modal e à relação de ordem que é definida no conjunto de mundos possíveis. Em ambas as línguas, é possível inferir que o subjuntivo será um modo por defeito, sendo seleccionado nos contextos em que o modo indicativo não o é. Finalmente, 
em ambas as línguas, existem predicados de gradação que expressam propriedades que induzem uma relação de ordem.

\section{REFERÊNCIAS}

HEIM, I. Pressupposition projection and the semantics of attitude verbs. Journal of Semantics, 9, 1992.

HOOPER, J. On assertive predicates. In: KIMBALL, J. (Ed.). Syntax and semantics. New York/Londres: Academic Press, 1975. Vol. 4.

KLEIN, F. Restricciones pragmáticas sobre la distribución del subjuntivo en español. In: Indicativo y subjuntivo. Madrid: Taurus Universitaria, 1990.

MARQUES, Rui. On the selection of mood in complement clauses. In: HOGEWEG, Lotte; HOOP, Helen de; MALCHUKOV, Andrej (eds.). Cross-linguistic Semantics of Tense, Aspect, and Modality. John Benjamins, 2009.

MARQUES, Rui. On the system of mood in European and Brazilian Portuguese. Journal of Portuguese Linguistics, 3, 2004.

MARQUES, Rui. Sobre a selecção de modo em orações completivas. In: Actas do XII Encontro Nacional da Associação Portuguesa de Linguística, Vol. I, Lisboa: Associação Portuguesa de Linguística, 1996.

MARQUES, Rui. Modality, context change potencial and mood selection in European Portuguese. In: BECKER, Martin; REMBERGER, Eva-Maria (eds.). Modality and Mood in Romance: modal interpretation, mood selection, and mood alternation. Linguistische Arbeiten 533, Niemeyer/de Gruyter, 2010.

MARQUES, Rui. Sobre a semântica dos "tempos" do conjuntivo. In: XXV Encontro da Portuguesa de Linguística. Textos Seleccionados. Porto: APL, 2009.

PALMER, F. Mood and Modality. Cambridge: Cambridge University Press, 1886.

PORTNER, P. Imperatives and modals. Natura Language Semantics, 15(4), 2007.

VILLALTA, Elisabeth. Mood and gradability: an investigation of the subjunctive mood in Spanish. Linguist and Philos. Tubingen, 2009 